\title{
Pushing Tumor Margin
}

National Cancer Institute

\section{Source}

National Cancer Institute. Pushing Tumor Margin. NCI Thesaurus. Code C53991.

Describes a tumor border with an expanding and smooth configuration. 